\title{
Random walk analysis of cave maps for exemplary gypsum caves- mazes of Western Ukraine
}

\author{
Tomasz Błachowicz $\odot ~{ }^{1}$, Viacheslav Andreychouk $\odot^{2}$, Krzysztof Domino $\odot^{3}$ \\ 'Institute of Physics - Center for Science and Education, Silesian University of Technology, Gliwice, Poland \\ ${ }^{2}$ Faculty of Geography and Regional Studies, University of Warsaw, Poland; czeslaw.andrejczuk@gmail.com \\ ${ }^{3}$ Institute of Theoretical and Applied Informatics of the Polish Academy of Sciences, Gliwice, Poland
}

\begin{abstract}
The paper presents a new method of quantitative parameterization of net geomorphological structures with the use of random walk formalism and an analysis of Hurst exponent distribution derived from random walk experiments. As examples, horizontally developed gypsum caves were elaborated. The provided methodology is able to uniquely characterize cave systems.
\end{abstract}

Keywords: cave networks, gypsum caves, random walk, Hurst exponent

\section{Introduction}

It is widely known that geological objects can be treated as fractals (Laverty 1987, Chilès 1988, Maramathas, Boudouvis 2006, Budge, Sharp 2008, Pardo-Igúzquiza et al. 2012). While a geometrical fractal can be created using mathematical operations (Mandelbrot, Van Ness 1968), a fractal character of natural cave systems is weakly predictable (Curl 1986, Andreychouk et al. 2013), since underlying processes of creation are stochastic (Havlin, Ben-Avraham 2002, Pardo-Igúzquiza et al. 2014). From this results a need for quantitative characterization of such geomorphological random phenomena.

In the present paper, we propose a new approach based on a stochastic numerical experiment carried out on digital maps of caves. Performed calculations are parameterized by so-called self-similarity exponent distributions. However, we do not directly address fractal properties of cave networks. The fractal analysis of caves can be found in our previous work (Andreychouk et al. 2013). The paper is arranged as follows. At the beginning, after the presentation of investigated cave networks and some explanations about base geomorphological mechanisms, a description of a random walk method is presented. Next, results of calculations carried out for three different maze caves (Western Ukraine) developed in gypsum are given. At the end conclusions are provided. The
Ukrainian Optymistychna, Ozerna and Kryshtaleva Caves were chosen on purpose, since they represent a unique example of large, two-dimensional morphological complexes. It is worth mentioning here that all considered caves are hypogene in general (Klimchouk 2009, Palmer 2011).

\section{Cave networks}

The chosen two-dimensional caves are the largest Miocene gypsum caves of Western Ukraine. Their total lengths of corridors are as follows: Optymistychna $(232 \mathrm{~km})$, Ozerna $(131.4 \mathrm{~km})$, and Kryshtaleva (22.6 $\mathrm{km})$ (Klimchouk 2012). The caves represent enormous and dense nets of underground passages suitable for statistical analysis. The areas of the caves range from 0.3 to $2.5 \mathrm{~km}^{2}$ (Klimchouk et al. 2000). A ratio of the area to a thickness of the gypsum layer $(\sim 20 \mathrm{~m})$ allows them to be treated as two-dimensional objects with a good approximation, however there is no formal standard vertical extent to define two-dimensional vs. three-dimensional caves.

From the geomorphological perspective, for the Ukrainian caves, the network of observed fissures constitutes the structural prerequisites of morphogenesis. Regular research concluded it is formed mainly by the subsequent overlapping of the two 
a)

b)

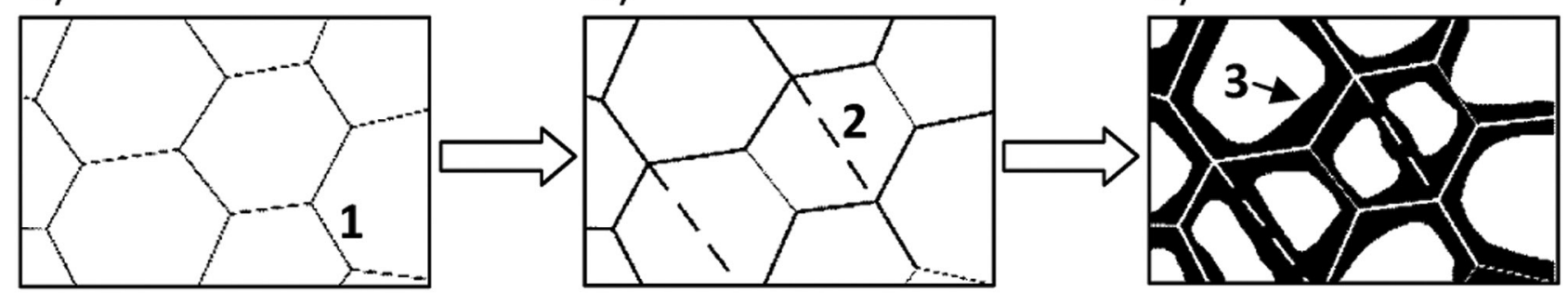

Fig. 1. Formation of fissure networks in gypsum layer due to the effect of tectonic stresses on the primary network of lithogenetic fissures

a) the primary polygonal network of fissures, b) the induction of the primary network by tectonic cracks, c) the developed cave labyrinth induced by the integrated network of fissures, 1 - the lithogenetic fissures, 2 - the newly-created tectonic cracks, 3 - the Cave corridors developed along fissures (Andreychouk 2007, Klimczouk 2009)

main fracturing systems of different origin, namely the lithogenetic and the tectonic (Klimchouk et al. 2009). This can result in the formation of structures with more or less regular geometrical properties the lithogenetic polygons and the tectonic rectangles (Fig. 1). A pre-speleogenetic spatial system is not created by independent superposition of these two local mechanisms, but by the integrated process, where the tectonic system of fissures evolves due to the existing distribution of strains, created by the adoption of primordial lithogenetic fissures. This results in a specific geometrical modifications and domination of some spatial directions (Klimchouk et al. 2009).

Importantly, in the case of caves being investigated here, we deal with distinct types of competitions between lithogenetic and tectonic contributions. The random walk analysis possesses an ability to resolve these effects quantitatively, what will be shown below.

\section{Research methodology}

The method of analysis investigates the morphological complexity represented by a cave map. A given map is transformed into a black-white picture so that all internal regions, corridors and passages, are black, while all outside regions are white. Next, information about spatial scales related to a single pixel size of digital images is classified, since it depends upon the scale at which the map is rasterized into grids. For the two-dimensional Optymistychna, Ozerna, and Kryshtaleva Caves, those sizes are equal to: $2.2 \times 2.2,2.2 \times 2.2$, and $0.5 \times 0.5 \mathrm{~m}^{2}$, respectively. Thus, the spatial scales of actual numerical images are roughly comparable, in the $\mathrm{x}$ and $\mathrm{y}$ dimensions, for all the investigated cases. The investigated image dimensions were equal to $3295 \times 2952,1936 \times 1437$, and $4048 \times 2983$ pixels for the Optymistychna, Ozerna, and Kryshtaleva, respectively.

As a next step of calculations, a random walk experiment is applied. It relies on virtual random mov- ing, beginning from a randomly chosen black pixel on the digital image of the cave. There are only four options that can be performed for a next step in the two-dimensional experiment - left, right, forward and backward. In a case of border pixel the walk is restricted only to three possibilities. Also, for a very rare case of the corner pixels only the two possibilities are accessible. The walk is repeated many times (it is numerical time of the walk) for the same starting point, and random distances obtained for random final points, are averaged to provide a single mean value of the resultant distance. Besides, the time of a walk, is varied within a range of values: beginning from a rational minimum of the $1 / 15$ part of the image shorter side (for example 2952/15 197 for the Optymistychna case) to a maximum value of the $1 / 2$ part of the shorter image side (for example $2952 / 2=1476$ for in the Optymistychna case). This choice of walk-times is quite arbitrary; in practice it should fall into the $10^{2}-10^{3}$ range for typical digital images.

Thus, for the given starting point chosen at random, we obtain a set of averaged resultant distances as a function of numerical time. The example of a single random walk experiment is presented in Figure 2. Next, the numerical experiment is repeated for different randomly chosen points (for example 1000), in order to test the whole image at different locations, and the final performed distance again is averaged for the given value of numerical time of walk.

In general, such a statistical experiment reveals the property, known from literature (Havlin, Ben-Avraham 2002), that an averaged squared random-walked distance increases naturally with time scale $t$ (represented here by the assumed number of random walk steps) in the following manner

$$
\left\langle r^{2}\right\rangle=A t^{2 H}
$$

where:

- $\left\langle r^{2}\right\rangle$ is the squared averaged distance obtained from repeated trials, 


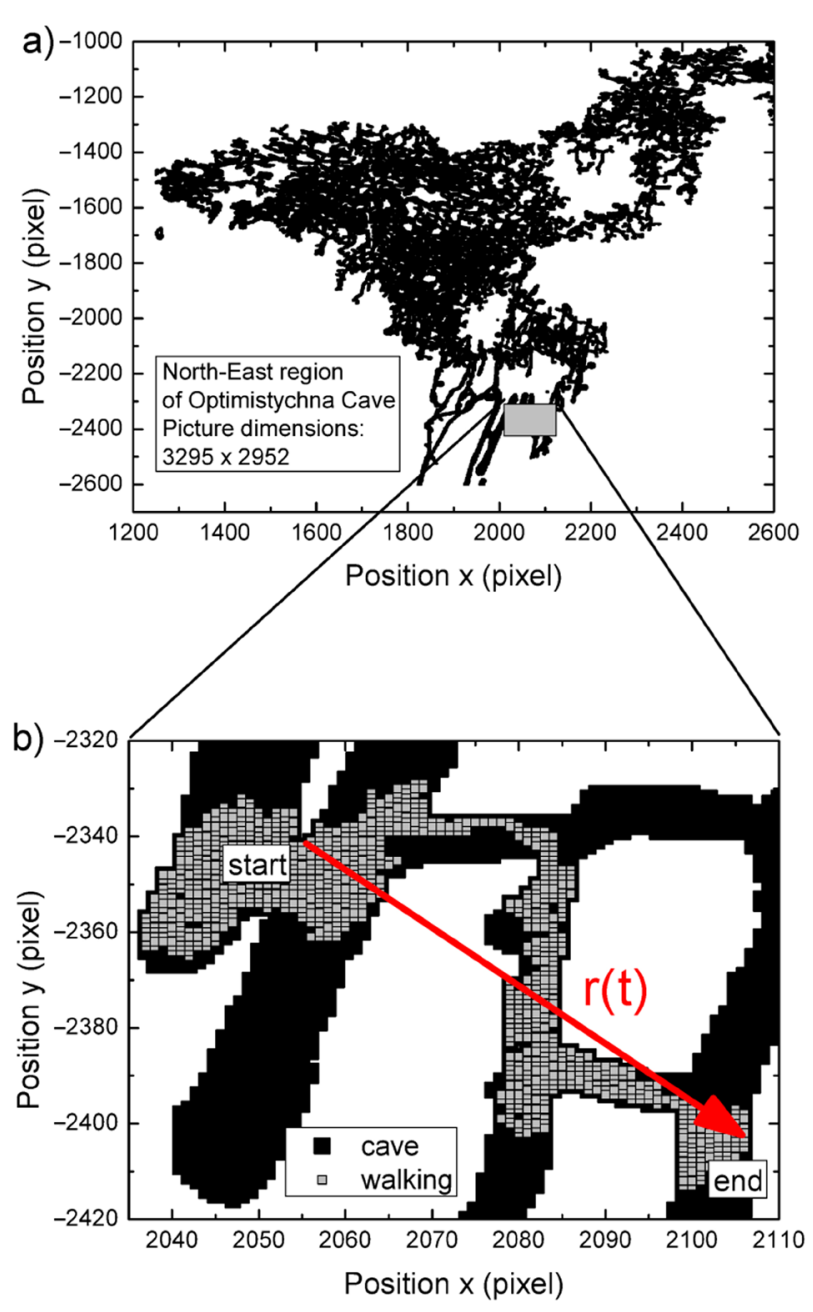

Fig. 2. An example of random walk experiment conducted at a monochromatic image of the Optymistychna Cave a) the starting point is chosen at random, and b) the enhanced trace positions of all walked steps; the obtained distance $r(t)$ can be calculated from coordinates of initial and final points

- $A$ is a constant, no important for our analysis,

- $H$ is the self-similarity exponent or the so called Hurst exponent.

The averaged distance for the purely random walk obviously vanishes, $\left\langle r^{2}\right\rangle=0$. From the statistical science point of view the Hurst exponent is an indicator of structural complexity and a type of correlation between subsequent random walks. For the $\mathrm{H}<0.5$ regime walks are negatively correlated, meaning that after a step in a given direction the next step in the same direction is less probable than in the back direction. For the $\mathrm{H}>0.5$ regime walks are positively correlated, meaning that after a step in a given direction the next step is the same direction is highly probable. The $\mathrm{H}=0.5$ case is the purely random walk with all four steps having equal probability and lack of correlations between them. For example, for the random walk taking place on a black rectangle, $H$ equals 0.5 (Fig. 3) and then Eq. 1 simplifies to $\left\langle r^{2}\right\rangle$

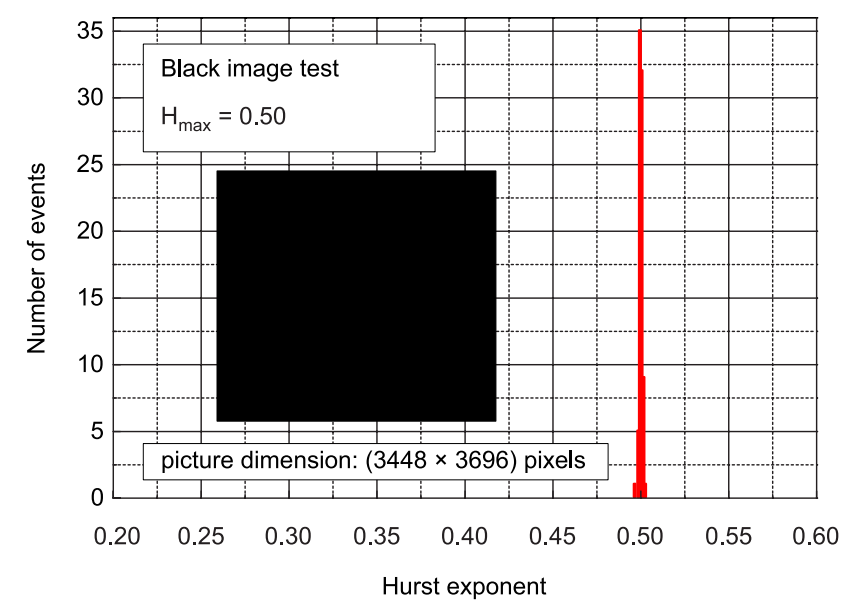

Fig. 3. The black image test performed inside a rectangle of $3448 \times 3696$ pixels size. The self-similarity exponent was determined as the very narrow peak with maximized value positioned at 0.50

$=A t$. From structural complexity point of view, the lower value of the $\mathrm{H}$ is, the smaller details take place in the map. However, in general, the square root of $\left\langle r^{2}\right\rangle$ scales in time as the power of an arbitrary $H$, namely

$$
\sqrt{\left\langle r^{2}\right\rangle}=\sqrt{A t^{H}}
$$

Thus, after calculating the logarithm of the above we obtain

$$
\log \sqrt{\left\langle r^{2}\right\rangle}=\frac{1}{2} \log A+H \log t
$$

Thus, after the simple logarithmic operation a linear dependence between the averaged distance $\sqrt{\left\langle r^{2}\right\rangle}$ and time $t$ is accessible, while the Hurst exponent $H$ is the adequate slope of the logarithmic graphs of $\sqrt{\left\langle r^{2}\right\rangle}$ vs. time. It is worth to emphasize that the Hurst exponent is the parameter obtained from the linear dependence (Eq. 3) and the given, concrete value of $H$ represents the averaged tendency to complete a given random distance starting from a random point at the image. Since for natural objects have complex structure, this tendency is local-dependent, then for such cases there no single value of $H$ but the whole set of possibilities, the distribution of $H$ exponents.

The quantitative method, presented in the current paper, relies on finding a self-similarity exponent distribution unique for a given cave map. The general rule is that the more tiny details took place at a map, and the more morphologically complex cave is, then lower values of $\mathrm{H}$ are obtainable. Values of $H$ significantly larger than 0.5 represent so called anomalous diffusion, and they are not encountered in geological objects (Feder 1988). 

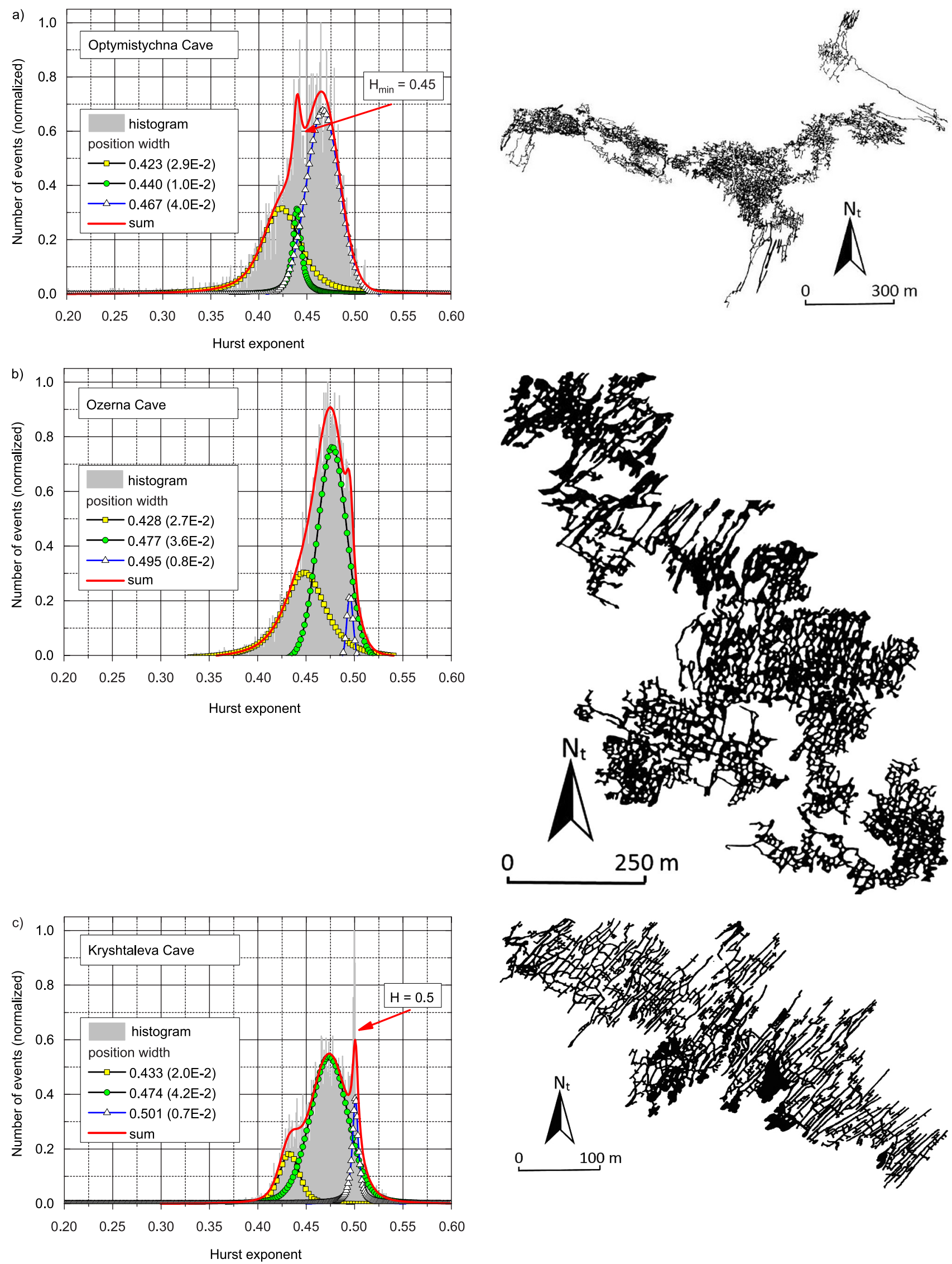

Fig. 4. The Hurst exponent distributions for three gypsum caves: a) Optymistychna Cave, b) Ozerna Cave, and c) Kryshtaleva Cave 


\section{Results and discussion}

The Hurst exponent distributions, calculated for the three caves along with fitted curves (components), are given in Figure 4. The fitting to histograms employs three Gaussian-shaped components of different peak-positions: $H_{1}, H_{2}$, and $H_{3}$ and widths: $w_{1}, w_{2}$, and $w_{3}$, and , enabling simplified, while quantitative, estimation of cave complexity. The fitting was carried out using Origin software.

Optymistychna Cave is an example of a quite diversified geological structure (Fig. 4a). The distribution of Hurst exponent values is relatively wider than the distributions of the other caves. The very characteristic for Optymistychna Cave is the narrow minimum localized at 0.45 that splits the histogram into two main components - the left one located at the similar position of 0.440 and the right one maximized at 0.467 . Obtained splitting and the existence of largest total width, among other caves, results from the very rich morphogenetic diversity.

The case of Ozerna Cave is different (Fig. 4b). The whole distribution is relatively narrow and characteristically shifted into the larger $H$ values. The obtained histogram is asymmetrically raised close to the 0.5 value. It is indicative for larger volumetric forms like rooms. Even if Ozerna does not really look uniform in morphology, i.e. the north-western sections of the cave appear to have more fissure morphology whereas the central and south parts of the cave have different maze morphology, the histogram of Figure $4 \mathrm{~b}$ is characteristically shifted mainly due to the north-western features.

Kryshtaleva Cave is quite different from the two mentioned above. In Figure 4c there is a very intense peak located at $H=0.50$ value, which is clearly interpretable as huge volumetric regions in the southern part of the cave and more dense maze in general. Additionally, the distribution is far from being smooth, and the $H>0.5$ contributions are relatively intensified. This is also understandable, since its geomorphological structure reveals dominating anisotropic, parallel passages, and in this sense this structure is more unidirectional - the passages enforce one-directional random walks in a given direction. Despite the 0.50 peak, the actual distribution has an intrinsic, separate, wide contribution positioned at the 0.474 , with the wide but less intense component located at
0.433. These two wide spread out components can be interpreted from a structural perspective, since it may be assumed that the cave has a system of two types of passages oriented mutually perpendicular. The similar spread of the values can be seen for the Ozerna Cave, and especially for the Optymistychna Cave, however the interpretation of these results requires future studies.

The calculated parameters are shown in Table 1. The parameters reveal that the degree of karstification, for the Ukrainian caves, can be correlated particularly with the third Hurst $\mathrm{H}_{3}$ exponent, located close to the 0.5 value. The second Hurst exponent $\mathrm{H}_{2}$, in histograms located centrally - and partially the first Hurst exponent $H_{1}$ - reflect a cave network diversity. These parameters are correlated with a cave porosity (Klimchouk 2007). The working rule can be expressed as follows: the smaller that the value of the Hurst exponent is, and the larger the component aerial intensity (the area under a given component fitted in the histogram) is, then the more intense the structural diversity takes place. This is why a first component pair of parameters $\left(H_{1}, w_{1}\right)$, distanced most away from 0.5 , can be associated with thinned lithogenetic structural predispositions for speleogenesis, while the third component pair of parameters $\left(H_{3}, w_{3}\right)$, located closely to the 0.5 value, are informative for more global tectonic predispositions. It is worth emphasizing that, the widths of fitted components can be treated as a measure of contribution of subsequent karstification factors. Obtained data are well correlated with an increasing order of growing porosity and passage density (Table 1). The greater values of Hurst exponents are indicative for the larger porosities and the passage densities.

\section{Conclusions}

The presented analysis of a cave structure with the use of Hurst exponent and a random walk method allowed for the quantitative description of uniformity and structural regularity of cave networks. The most informative in the presented analysis was the self-similarity (Hurst) exponent distribution, its spectral components of characteristic shapes and positions.

Table 1. Parameters of Hurst exponent histograms (Fig. 4), positions of components maxima $(H)$ and its widths $(w)$. Porosities and passage densities after (Klimchouk 2007)

\begin{tabular}{|c|c|c|c|c|c|c|c|c|}
\hline \multirow{2}{*}{ Caves } & $H_{1}$ & $w_{1}$ & $\mathrm{H}_{2}$ & $w_{2}$ & $\mathrm{H}_{3}$ & $w_{3}$ & Porosity & Passage density \\
\hline & \multicolumn{6}{|c|}{$[-]$} & {$[\%]$} & {$\left[\mathrm{km} \mathrm{km}^{-2}\right]$} \\
\hline Optymistychna & 0.423 & 0.029 & 0.440 & 0.010 & 0.467 & 0.040 & 2.00 & 127.03 \\
\hline Ozerna & 0.428 & 0.027 & 0.477 & 0.036 & 0.495 & 0.080 & 5.04 & 150.00 \\
\hline Kryshtaleva & 0.433 & 0.020 & 0.474 & 0.042 & 0.501 & 0.070 & 6.04 & 169.23 \\
\hline
\end{tabular}


The distribution shape is uniquely characterized by its width and the level of its symmetry. Obtained shapes reflect the level of morphological uniformity or diversity of local structure. If cave parts are significantly different from contractual average, and their structure is more diverse and chaotic, then the Hurst exponent distribution is more spread in values, non-uniform and can even have local maxima and minima. On the other hand, if the Hurst exponent distribution is narrower, then the cave network structure can be more ordered, anisotropic and regular. Comparing two-dimensional caves (Fig. 4, Tab. 1) it becomes obvious that Optymistychna Cave has the lowest level of morphogenetic diversity, while the Ozerna and Kryshtaleva Caves have the larger one.

A shift of distribution into the smaller values of Hurst exponent scale, is indicative of the existence of more localized structural features. If a distribution is shifted towards the 0.5 value, then it is characteristic for the existence of large empty spaces (halls) or the existence of very dense, random networks of closely located passages or fissures. Comparing obtained distributions with maps of caves, it becomes quite clear that Kryshtaleva Cave has the largest rooms which stand out from a normal system of passages. A similar property, but less evident, was also detected in Ozerna Cave as indicated by more dense maze located in several places (Fig. 4b).

Taking into account all the parameters of histograms we conclude that the morphogenesis of Kryshtaleva Cave results mostly from the contribution of tectonic restructuring of primary fissure networks. Consequently, this tectonic-based restructuring is less important for Ozerna Cave, and even less for Optymistychna Cave. Their networks are very diverse, heterogeneous, and referring to the primary polygonal system of cracks, less modified by tectonics.

Despite the sophisticated structural complexity of geological objects, we found the proposed numerical methodology as useful for parameterization purposes by introducing new quantitative parameters characterizing morphology of hypogene cave-mazes. The authors believe that further research efforts are desirable to better understand speleogenesis of the wider class of two-dimensional and three-dimensional geological systems with the use of the random walk numerical experiments and self-similarity analysis.

\section{Authors' contributions}

Tomasz Błachowicz: 50\%, Viacheslav Andreychouk: 40\%, Krzysztof Domino: $10 \%$.

\section{References}

Andreychouk V.N., 2007. Zoloushka Cave. Faculty of Earth's Sciences, University of Silesia and Ukrainian Institute of Speleology and Karstology, Sosnowiec-Symferopol: 1-408.

Andreychouk V., Blachowicz T., Domino, K., 2013. Fractal dimensions of cave for exemplary gypsum cave-mazes of Western Ukraine. Landform Analysis 22: 3-8.

Budge T.J., Sharp Jr. J.M., 2008. Modeling the usefulness of spatial correlation analysis on Karst systems. Ground Water 47: 427-437.

Chilès J.P., 1988. Fractal and geostatistical methods for modeling of a fracture network. Mathematical Geology 20: 631-654.

Curl R.L., 1986. Fractal dimensions and geometries of caves. Mathematical Geology 18: 765-783.

Feder J., 1988. Fractals. Plenum, New York.

Havlin S., Ben-Avraham D., 2002. Diffusion in disordered media. Advances in Physics 51: 187-292.

Klimchouk A.B., 2000. Speleogenesis in Gypsum. In: A.B.Klimchouk, D.C.Ford, A.N.Palmer, W.Dreybrodt (eds), Speleogenesis: Evolution of Karst Aquifers, National Speleological Society, Huntsville, Alabama.

Klimchouk A.B., 2007. Hypogene Speleogenesis: Hydrogeological and Morphogenetic Perspective. National Cave and Karst Research Institute, Carlsbad, NM, Special Paper no. 1: 1-106.

Klimchouk A.B., 2009. Morphogenesis of hypogenic caves. Geomorphology 106(1-2): 100-117.

Klimchouk A.B., 2012. Ukraine giant gypsum caves. In: W.B.White, D.C.Culver (eds), Encyclopedia of Caves, Elsevier: 827-833.

Klimchouk A.B., Andreychouk V.N., Turchinov I.I., 2009. The structural prerequisites of speleogenesis in gypsum in the Western Ukraine. University of Silesia - Ukrainian Institute of Speleology and Karstology, Sosnowiec-Simferopol, 2nd edition, revised: 1-96.

Laverty M., 1987. Fractals in karst. Earth Surface Processes and Landforms 12(5): 475-480.

Mandelbrot B.B., Van Ness J.W., 1968. Fractional Brownian motions, fractional noises and applications. SIAM Review 10(4): 422-437.

Maramathas A.J., Boudouvis A.G., 2006. Manifestation and measurement of the fractal characteristics of karst hydrogeological formations. Advances in Water Resources 29(1): 112-116.

Palmer A.N., 2011. Distinction between epigenic and hypogenic maze caves. Geomorphology 134(1-2): 9-22.

Pardo-Igúzquiza E., Dowd P.A., Xu C., Durán-Valsero J.J., 2012. Stochastic simulation of karst conduit networks. Advances in Water Resources 35: 141-150.

Pardo-Igúzquiza E., Durán J.J, Robledo R., Guardiola C., Luque J.A., Martos S., 2014. Fractal Modeling of Karst Conduits. Lecture Notes in Earth System Science, Mathematics of Planet Earth: Proceedings of the 15th Annual Conference of the International Association for Mathematical Geosciences, Springer, Berlin, Heidelberg: 217-220. 